\title{
Characterization of Phytophthora spp. Causing Outbreaks of Citrus Brown Rot in Florida
}

\author{
J. H. Graham, L. W. Timmer, D. L. Drouillard, and T. L. Peever
}

University of Florida, IFAS, Citrus Research and Education Center, 700 Experiment Station Road, Lake Alfred 33850.

Accepted for publication 1 April 1998.

\begin{abstract}
Graham, J. H., Timmer, L. W., Drouillard, D. L., and Peever, T. L. 1998. Characterization of Phytophthora spp. causing outbreaks of citrus brown rot in Florida. Phytopathology 88:724-729.

Epidemics of citrus brown rot from 1994 to 1997 in the south-central and east-coast citrus areas of Florida were characterized and the causal Phytophthora spp. identified. Two species of Phytophthora, P. palmivora and $P$. nicotianae, were consistently associated with brown rot. Epidemics caused by $P$. palmivora appeared to be initiated on immature fruit dropped on the orchard floor. The soilborne fungus infected and sporulated on these fruit and was then disseminated to fruit above $1 \mathrm{~m}$ in the canopy. In contrast, infection by $P$. nicotianae, the common cause of root rot, was confined to the lowest $1 \mathrm{~m}$ of the canopy. Fruit infected by $P$. palmivora produced large amounts of ellipsoidal sporangia available for

splash dispersal, whereas those infected by $P$. nicotianae produced far fewer spherical sporangia. Isolates from brown rot epidemics were compared with P. nicotianae from citrus in Florida and Texas, P. citrophthora in California, P. palmivora, and selected Phytophthora spp. from other hosts. Brown rot symptoms produced by the different pathogenic citrus isolates on inoculated fruit were indistinguishable. Morphology, mating behavior, and isozyme patterns of brown rot isolates from 1988 to 1997 matched $P$. palmivora from citrus roots, other host plants, and other locations, but were different from characterized isolates of $P$. citrophthora in California and $P$. nicotianae in Florida and Texas. Cellulose acetate electrophoresis of the isozyme glucose-6-phosphate isomerase rapidly identified the causal citrus pathogen from infected fruit and soil isolation plates. Although $P$. palmivora is an aggressive pathogen of citrus roots, bark, and fruit, populations in orchard soils were low compared with P. nicotianae.
\end{abstract}

Brown rot epidemics of early-season orange varieties have occurred sporadically in the fall in the east-coast and south-central citrus areas of Florida citrus since the early 1950s (9,17). Epidemic seasons are commonly associated with periods of prolonged wetness exceeding 7 days and with temperatures in the diurnal range of 23 to $32^{\circ} \mathrm{C}$ coinciding with the maturation (i.e., color development) of early- and mid-season oranges and grapefruit $(5,6,9)$. Under these circumstances, fruit infected by Phytophthora nicotianae Breda de Haan (synanamorph $P$. parasitica Dastur), the common causal agent of foot rot and root rot in citrus orchards, is restricted to the lower portion of the canopy below $1 \mathrm{~m}$ in height. $P$. nicotianae is a minor brown rot pathogen because it produces few sporangia on the fruit surface, and thus, propagules are not available to be splashed to fruit higher in the tree.

Whiteside (18) reported on the factors related to the restricted occurrence of brown rot during September to October 1968 and 1969 , caused by a Phytophthora sp. that spread high (>1 m) into the tree canopy and rapidly produced abundant sporangia on infected fruit. The causal fungus from several orchards was identified as $P$. citrophthora (R. E. Smith \& E. H. Smith) Leonian. The restricted nature of the epidemics was attributed to the sporadic occurrence of prolonged rainfall events in the fall when early- and mid-season varieties are susceptible to infection (18). The limited distribution of $P$. citrophthora also explained why the outbreaks were confined to certain orchard locations, even though susceptible varieties and favorable conditions for disease occurred in other regions of the industry.

In fall 1994 and 1995, outbreaks of a Phytophthora sp. resembling P. palmivora (Butler) Butler were reported in certain locations throughout the south-central and coastal regions of Florida

Corresponding author: J. H. Graham; E-mail address: jhg@icon.lal.ufl.edu

Publication no. P-1998-0518-02R

(C) 1998 The American Phytopathological Society
(6). In one case, in the aftermath of Hurricane Gordon, several hundred hectares were affected with losses up to $90 \%$, while more typical losses were in the $30 \%$ range over areas of 10 to 20 ha. Although $P$. palmivora has been recovered from soil in Florida in two east-coast locations (20), this Phytophthora sp. was previously only reported as a widespread citrus pathogen in the warm tropics, but with no supporting data (8). In greenhouse and in vitro studies, Zitko and Timmer (19) demonstrated that $P$. palmivora was a more aggressive and competitive pathogen of citrus roots, stems, and fruit tissues than was $P$. nicotianae.

The purpose of this study was to elucidate the cause of epidemics of brown rot in Florida from 1994 to 1997. The primary objective was to isolate and characterize Phytophthora spp. from several brown rot epidemics using morphological methods, pathogenicity and symptoms on citrus fruit, mating behavior, and cellulose acetate electrophoresis (CAE) for isozyme analysis. In addition, the distinguishing features between the epidemiology of $P$. palmivora and $P$. nicotianae in orchards with a history of brown rot epidemics are described together with a diagnostic method to rapidly identify which Phytophthora sp. caused the outbreak.

\section{MATERIALS AND METHODS}

Isolations from brown rot-affected fruit. From September to December 1994, fruit of Hamlin sweet orange (Citrus sinensis (L.) Osbeck) with a light brown, leathery decay was sampled from eight brown rot epidemics in Polk County in the central region of the Florida citrus industry and in Hardee, Desoto, and Hendry counties in the south-central region. In January 1995, white grapefruit (C. paradisi Macf.) with postharvest brown rot was obtained from a packinghouse in Indian River County on the east coast. From August to October 1995, an additional 22 orchards of Hamlin orange, one orchard of Temple tangor (C. reticulata Blanco hybrid), and blocks of Hamlin, Midsweet, and Pineapple sweet orange in the same location were sampled in Polk, Highlands, and Hardee counties. From June to November 1995, daily rainfall measure- 
ments were recorded in five of the orchards in southern Polk and Highlands counties where the first symptoms of disease were confirmed by fungal isolations from fruit.

Isolations of Phytophthora spp. from symptomatic fruit were made by placing pieces of the affected fruit rind without surfacesterilization onto plates of selective PARPH (pimaricin-ampicillinrifampicin-pentachloronitrobenzene-hymexazol) agar modified as previously described (15). Isolation of Phytophthora spp. was also accomplished by placing one to three fruit in a resealable plastic bag with sterile distilled water and shaking the bag to wash the sporangia from the fruit surface. The rinse water was examined under the light microscope for the presence of sporangia, and sporangial characteristics such as the abundance, shape, and lengthto-breadth ratio were noted. The rinse water was then spread directly on modified PARPH medium. In general, five isolates of Phytophthora spp. were collected from each location.

Isolations from fallen fruit and soil. Isolations of Phytophthora spp. from symptomless green fruit (trap fruit) or from soil were made in a heavily diseased orchard in southern Polk County (Bereah) from 1995 to 1997. In September 1995 and August 1997, immature green fruit of Hamlin orange approximately $4 \mathrm{~cm}$ in diameter was used to trap Phytophthora spp. from the soil in the orchard. Symptomless fruit were placed on the ground under trees with brown rot symptoms on the lower $1 \mathrm{~m}$ of the canopy in a 10-ha area of the orchard. After 72 h, 10 fruit each from seven locations in the orchard were combined in a resealable plastic bag and transported immediately to the laboratory. The fruit-washing method described above was used for isolation of Phytophthora spp., except that the bags were placed on a rotary shaker at $100 \mathrm{rpm}$ for $1 \mathrm{~h}$ prior to plating the rinse water on PARPH.

In July and September 1996 and 1997, before and after the appearance of brown rot in the orchard, $22100-\mathrm{cm}^{3}$ soil samples were combined into resealable plastic bags for eight 0.1-ha locations within the same orchard. For isolations, subsamples of soil were spread onto PARPH medium using procedures previously developed for estimating populations of $P$. nicotianae (15). After a 3-day incubation at $27^{\circ} \mathrm{C}$, colonies that were smaller and more compact than $P$. nicotianae were counted and isolated for further study.
Mating and pathogenicity tests. Cultures were maintained and fungal structures were produced on clarified V8 juice agar (CV8A) or broth (CV8-B) as described by Mitchell et al. (11). For sporangium production, 2-day-old cultures in CV8-B were washed with sterile distilled water and incubated for two additional days at room temperature. Cultures were chilled for $15 \mathrm{~min}$ at $5^{\circ} \mathrm{C}$ and then returned to room temperature to induce zoospore production. Chlamydospores were produced by the method of Tsao (16) and separated from mycelium by repeated blending and low-speed centrifugation for observations.

Matings were conducted on CV8-A in the dark at $27^{\circ} \mathrm{C}$ by pairing isolates from brown rot epidemics with isolates of $P$. citrophthora from citrus, with previously characterized A1 and A2 mating types of $P$. palmivora from citrus and cacao, and with $P$. nicotianae from citrus (Table 1) (20).

For fruit inoculations, mature Valencia sweet orange fruit were collected from the field, rinsed with water, and surface-disinfested by wiping with $70 \%$ ethanol. Fruit were placed in closed plastic chambers on wire mesh stands to suspend them above a 2-cm-deep water reservoir. Five $0.05-\mathrm{ml}$ droplets containing $10^{5}$ zoospores per $\mathrm{ml}$ were placed on the surface of each fruit without wounding. Chambers were incubated in the laboratory at 25 to $27^{\circ} \mathrm{C}$ for 7 days. The number of fruit with brown rot symptoms was counted, and reisolations for identification of the fungus from infected fruit tissue were performed as described in the previous and following sections.

CAE. A CAE method developed by Goodwin et al. (2) was used for isozyme analysis with modifications. Sterilized cellophane disks were placed on the surface of corn meal agar (CMA) and incubated for 1 day to insure that no bacterial contamination occurred before seeding of the cellophane surface of the agar with Phytophthora spp. The CMA cultures were grown at $27^{\circ} \mathrm{C}$ for 3 to 4 days prior to scraping the mycelium from the surface with a spatula for transfer to a microcentrifuge tube. The mycelium was ground for $30 \mathrm{~s}$ with a tissue homogenizer that closely fit the contours of the microcentrifuge tube and then frozen at -5 or $-80^{\circ} \mathrm{C}$ for shortand long-term storage, respectively. Several different enzyme and running buffer combinations were tested with 45 to 85 min run times: glucose-6-phosphate dehydrogenase, glucose-6-phosphate iso-

TABLE 1. Phytophthora spp. isolated from citrus in Florida, California, Texas, and from other hosts

\begin{tabular}{|c|c|c|c|c|}
\hline Isolate & Species & Origin and isolation date & Host/source & Reference \\
\hline P29 & P. palmivora & Florida 9/94 & Citrus fruit & This study \\
\hline $\mathrm{P} 44 \mathrm{~b}$ & P. palmivora & Florida 10/94 & Citrus fruit & This study \\
\hline P48 & P. palmivora & Florida 1/95 & Citrus fruit & This study \\
\hline P67-1 & P. palmivora & Florida $8 / 95$ & Citrus fruit & This study \\
\hline P99-59-1 & P. palmivora & Florida $9 / 95$ & Citrus fruit & This study \\
\hline P101-16 & P. palmivora & Florida $9 / 96$ & Citrus fruit & This study \\
\hline P107-9 & P. palmivora & Florida 2/97 & Citrus soil & This study \\
\hline EB-1 & P. palmivora & Florida $9 / 88$ & Citrus fruit & Literature citation 18 \\
\hline EB-3 & P. palmivora & Florida $9 / 92$ & Citrus fruit & G. E. Brown \\
\hline Plt B & P. palmivora & Florida 10/88 & Citrus soil & Literature citation 18 \\
\hline Sh-I & P. palmivora & Florida 12/89 & Citrus soil & Literature citation 18 \\
\hline PL-10 & P. palmivora & Costa Rica 12/92 & Cacao pod & D. J. Mitchell \\
\hline P66 & P. palmivora & Florida 10/92 & Milkweed Morrenia odorata & Literature citation 1, ATCC 52158 \\
\hline Dd-1 & P. nicotianae & Florida 1/91 & Citrus soil & L. W. Timmer \\
\hline Riv-1 & P. nicotianae & Florida $6 / 88$ & Citrus soil & L. W. Timmer \\
\hline P101-2 & P. nicotianae & Florida $9 / 96$ & Citrus fruit & This study \\
\hline P95-01 & P. nicotianae & Texas 1995 & Citrus soil & M. Skaria \\
\hline P92-19 & P. nicotianae & Texas 1992 & Citrus soil & M. Skaria \\
\hline P91-28 & P. nicotianae & Texas 1991 & Citrus foliage & M. Skaria \\
\hline M140 & P. citrophthora & California 1988 & Citrus soil & J. A. Menge \\
\hline M189 & P. citrophthora & California 1990 & Citrus roots & J. A. Menge \\
\hline M259 & P. citrophthora & California 1993 & Citrus bark & J. A. Menge \\
\hline M263 & P. citrophthora & California 1994 & Citrus bark & J. A. Menge \\
\hline M214 & P. citricola & California 1991 & Avocado & J. A. Menge \\
\hline M265 & P. citricola & California 1994 & Avocado & J. A. Menge \\
\hline M224 & P. citricola & California 1991 & Alfalfa & J. A. Menge \\
\hline M256 & P. cactorum & California 1993 & Not determined & J. A. Menge \\
\hline PA3-1 & P. arecae & Florida 1986 & Bamboo palm Chamaedorea hybrid & Literature citation 14, ATCC 64558 \\
\hline P94-15B & P. capsici & New Mexico 1994 & Chili pepper & M. Skaria \\
\hline
\end{tabular}


merase, isocitrate dehydrogenase, hexokinase, malate dehydrogenase, malate dehydrogenase $\mathrm{NADP}^{+}$, mannose-6-phosphate isomerase, peptidase, and phosphoglucomutase. The running buffers and reagents were as recommended by Hebert and Beaton (7). Electrophoretic phenotypes were identified by measuring the distance, in millimeters, of migration from the loading well for a selected band for each enzyme. Setting that distance as 100, other bands were designated by dividing their distance of migration by the selected band and multiplying the ratio by 100 .

\section{RESULTS}

Description of brown rot epidemics. Outbreaks of brown rot in 1994 and 1995 were most prevalent from August to October in the south-central area of the industry in orchards surrounded by native oak, pine, and palm hammocks that are seasonally flooded. The orchards were usually level and often supported trees more than $5 \mathrm{~m}$ in height that formed hedge rows that restricted air movement. In late August and early September 1995, epidemics in five orchards of 20- to 40-year-old Hamlin orange trees occurred after 9 to 12 rain events of at least $2.5 \mathrm{~mm}$ in 21 days prior to brown rot symptoms (data not shown). Subsequent epidemics in the same locations in late September and early October 1995 appeared after five to seven rain events over 7- to 10-day periods. Rainfall per event often, but not always, increased prior to the epidemic.

Fruit with brown rot collected more than $1 \mathrm{~m}$ high in the tree canopy produced high densities of monopapillate, ellipsoidal sporangia from the surface, whereas fruit from brown rot confined to below $1 \mathrm{~m}$ in height in the canopy formed a few, spherical sporangia on the surface. Phytophthora spp. isolated from brown rot distributed higher in the tree produced small compact colonies with sporangia present on PARPH medium 3 days after isolation. Colonies from fruit in locations where brown rot was distributed low in the canopy were fast growing with no sporangia produced on PARPH medium after 3 days.

Isolations from fallen fruit and soil. In September 1995 and August 1997 at Bereah, four of seven and four of six samples of asymptomatic green fruit yielded Phytophthora spp. when collected $72 \mathrm{~h}$ after they were placed on the orchard floor. P. palmivora and $P$. nicotianae were each recovered from two of the four fruit samples positive for Phytophthora spp. at both sampling times. In August 1996, before brown rot symptoms were observed in the orchard, $P$. palmivora was not recovered from the soil. However, soil populations of $P$. nicotianae were high (60 propagules per $\left.\mathrm{cm}^{3}\right)$. In October 1996, brown rot was present at low levels and $P$. nicotianae populations were lower (15 propagules per $\mathrm{cm}^{3}$ ) compared with populations in August. P. palmivora was recovered from four of eight soil samples, ranging from 1 to 4 propagules per $\mathrm{cm}^{3}$. In July and August 1997, P. palmivora was detected in 3 of 22 soil samples on each occasion, ranging from 2 to 14 propagules per $\mathrm{cm}^{3}$. Soil populations of $P$. nicotianae were significantly $(t$ test, $\mathrm{df}=15$, $P \leq 0.05$ ) lower in 1997 (11 propagules per $\mathrm{cm}^{3}$ ) than in 1996.

Morphological and pathological characterization. When cultured in CV8-B, isolates from brown rot collected more than $1 \mathrm{~m}$ high in the tree canopy yielded sporangia that were highly caducous and ellipsoidal with a length/breadth (L/B) ratio of 1.6 to 1.8 and readily produced chlamydospores in submerged broth cultures at $18^{\circ} \mathrm{C}$. Sporangia from isolates recovered from brown rot distributed near the soil surface were spherical, noncaducous, and had a L/B of 1.2 to 1.3 in CV8-B (P101-2) (Table 2). Isolates with spherical sporangia were indistinguishable morphologically from $P$. nicotianae, the species commonly associated with root rot and foot rot of citrus in Florida $(5,6)$. Isolates with ellipsoidal sporangia from 32 of the 36 brown rot epidemics surveyed were similar to soilborne isolates from orchards on the east coast collected in 1988 and 1989 and identified as P. palmivora (Table 2) (20). Florida brown rot

TABLE 2. Morphological characteristics, mating behavior, and isozyme phenotypes for glucose-6-phosphate isomerase (GPI) and malate dehydrogenase (MDH) of Phytophthora spp. isolated from citrus in Florida, Texas, California, and from other hosts

\begin{tabular}{|c|c|c|c|c|c|}
\hline \multirow[b]{2}{*}{ Isolate } & \multirow[b]{2}{*}{ Species } & \multirow[b]{2}{*}{ Sporangial characteristics } & \multirow[b]{2}{*}{ Mating type ${ }^{a}$} & \multicolumn{2}{|c|}{ Isoenzyme phenotypes ${ }^{b}$} \\
\hline & & & & GPI & $\mathrm{MDH}$ \\
\hline P29 & P. palmivora & Ellipsoid, caducous & A1 & $97 / 106 / 112$ & $108 / 120$ \\
\hline $\mathrm{P} 44 \mathrm{~b}$ & P. palmivora & Ellipsoid, caducous & A1 & $97 / 106 / 112$ & $108 / 120$ \\
\hline P48 & P. palmivora & Ellipsoid, caducous & A1 & $97 / 106 / 112$ & $108 / 120$ \\
\hline P67-1 & P. palmivora & Ellipsoid, caducous & A1 & $97 / 106 / 112$ & $108 / 120$ \\
\hline P99-59-1 & P. palmivora & Ellipsoid, caducous & A1 & $97 / 106 / 112$ & $108 / 120$ \\
\hline P101-16 & P. palmivora & Ellipsoid, caducous & A1 & $97 / 106 / 112$ & $108 / 120$ \\
\hline P107-9 & P. palmivora & Ellipsoid, caducous & A1 & $97 / 106 / 112$ & $108 / 120$ \\
\hline EB-1 & P. palmivora & Ellipsoid, caducous & A1 & $97 / 106 / 112$ & $108 / 120$ \\
\hline EB-3 & P. palmivora & Ellipsoid, caducous & A1 & $97 / 106 / 112$ & $108 / 120$ \\
\hline Plt B & P. palmivora & Ellipsoid, caducous & A1 & $97 / 106 / 112$ & $108 / 120$ \\
\hline Sh-I & P. palmivora & Ellipsoid, caducous & A1 & $97 / 106 / 112$ & $108 / 120$ \\
\hline PL-10 & P. palmivora & Ellipsoid, caducous & A2 & $97 / 106 / 112$ & $108 / 120$ \\
\hline P66 & P. palmivora & Ellipsoid, weakly caducous & A2 & $97 / 106 / 112$ & $108 / 120$ \\
\hline Dd-1 & P. nicotianae & Spherical, noncaducous & A1 & 100 & $100 / 112$ \\
\hline Riv-1 & P. nicotianae & Spherical, noncaducous & A2 & 100 & $100 / 112$ \\
\hline P101-2 & P. nicotianae & Spherical, noncaducous & A1 & 100 & $100 / 112$ \\
\hline P95-01 & P. nicotianae & Spherical, noncaducous & A2 & 100 & $100 / 112$ \\
\hline $92-19$ & P. nicotianae & Spherical, noncaducous & ND & 100 & $100 / 112$ \\
\hline P91-28 & P. nicotianae & Spherical, noncaducous & A1 & 100 & $100 / 112$ \\
\hline M140 & P. citrophthora & Highly variable, weakly caducous & $\ldots$ & 94/107 & $104 / 116$ \\
\hline M189 & P. citrophthora & Highly variable, weakly caducous & $\ldots$ & $94 / 107$ & $104 / 116$ \\
\hline M259 & P. citrophthora & Highly variable, weakly caducous & $\ldots$ & $94 / 107$ & $104 / 116$ \\
\hline M263 & P. citrophthora & Highly variable, weakly caducous & $\ldots$ & $94 / 107$ & $104 / 116$ \\
\hline M214 & P. citricola & Ovoid-obpyriform, noncaducous & $\mathrm{H}$ & 65 & $100 / 112$ \\
\hline M265 & P. citricola & Ovoid-obpyriform, noncaducous & $\mathrm{H}$ & 65 & $100 / 112$ \\
\hline M224 & P. citricola & Ovoid-obpyriform, noncaducous & $\mathrm{H}$ & 94 & $96 / 114$ \\
\hline M256 & P. cactorum & Ovoid, caducous & ND & 97 & $94 / 111$ \\
\hline PA3-1 & P. arecae & Ovoid-obpyriform, caducous & A 1 & 108 & $108 / 120$ \\
\hline P94-15B & P. capsici & Ellipsoid, noncaducous & ND & 106 & $104 / 114$ \\
\hline
\end{tabular}

a $\mathrm{ND}=$ not determined, and $\mathrm{H}=$ homothallic.

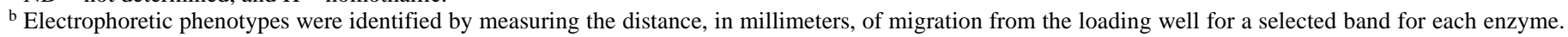
Setting that distance as 100, other bands were designated by dividing their distance of migration by the selected band and multiplying the ratio by 100 . 
isolates also closely resembled $P$. palmivora isolates from cacao (Theobroma cacao) in Costa Rica (PL10) and milkweed vine (Morrenia odorata) in Florida (P66). The latter P. palmivora isolate, now marketed as a biological control agent (Devine) for milkweed vine, was originally identified as $P$. citrophthora (1).

Sporangia from brown rot isolates did not resemble $P$. citrophthora isolates from California, which were weakly caducous and highly variable in shape, size, and L/B ratio (1.2 to 1.9) (Table 2). $P$. citrophthora isolates produced bipapillate as well as monopapillate sporangia in CV8-B cultures, but did not form chlamydospores in submerged culture. Although isolates from brown rot epidemics prior to 1994 were morphologically similar to $P$. palmivora, in Florida they were routinely identified as $P$. citrophthora (e.g., EB-1, EB-3) (cf. 18) as reported for epidemics in the 1960s (18).

Pathogenicity of putative $P$. palmivora isolates was confirmed by zoospore inoculation of Valencia orange fruit. Disease symptoms were the same as those produced by isolates of $P$. nicotianae from Florida (Dd-1, Riv-1) and Texas (P91-28), and P. citrophthora isolates from California (M259, M189, and M263) (Table 1). $P$. palmivora isolates from cacao and milkweed vine were not pathogenic to fruit after repeated inoculation attempts. All putative $P$. palmivora isolates from Florida brown rot were A1 and mated readily with the A2 isolates from cacao and milkweed vine, as well as with A2 isolates of $P$. nicotianae (Table 2). Isolates of $P$. citrophthora failed to produce oospores in pairings with other species of either mating type or among themselves.

CAE. The CAE method for isozyme analysis identified each morphological species examined as a unique electrophoretic type, with only a few exceptions (Table 2). Several different enzyme and running buffer combinations were tested, with the following producing adequate activity after 45- to 85-min run times: glucose-6-phosphate isomerase (GPI) in Tris glycine buffer and malate dehydrogenase (MDH) in citric acid-4-(3-aminopropyl) morpholine buffer. Other enzyme-buffer combinations failed to give adequate activity or resolution consistently. The three citrus pathogens produced distinctive banding patterns with GPI (Fig. 1). The single band produced by $P$. nicotianae was used as the standard to calculate the pattern phenotypes for species identification purposes. $P$. palmivora produced three bands similar to that reported for $P$. infestans (2): one more intense band between the other two bands. In the case of $P$. citrophthora, the pattern was a primary band and secondary band of lesser intensity.

The same comparisons were made for the isoenzyme patterns produced by MDH (Table 2). The results for the two-enzyme analysis were reinforcing. Each Phytophthora sp. produced a unique migration distance or banding pattern for each enzyme, with two exceptions (Table 2, Fig. 2). The MDH phenotype for P. palmivora was similar to the two isolates of $P$. arecae from bamboo palm (Chamaedorea hybrid), and P. nicotianae was similar to the two $P$. citricola isolates from avocado (Tables 1 and 2).

The GPI and MDH patterns for brown rot isolates collected from 1995 to 1997 were indistinguishable from each other and from isolates of $P$. palmivora from citrus soil and milkweed vine

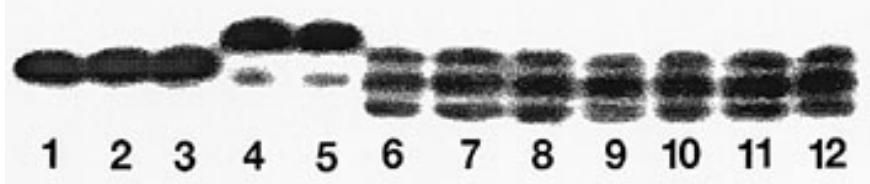

Fig. 1. Cellulose acetate electrophoresis of the isozyme glucose-6-phosphate isomerase for brown rot isolates from Florida compared with isolates of Phytophthora nicotianae from Florida and Texas, isolates of $P$. citrophthora from California, and P. palmivora from another location and host plant. Lanes 1 to 3 are P. nicotianae isolates Dd-1, P101-2, and P95-01; lanes 4 and 5 are $P$. citrophthora isolates M259 and M189; lanes 6 to 11 are P. palmivora isolates P44b, P48, P67-1, P99-59-1, P101-16, and P107-9; and lane 12 is $P$. palmivora isolate PL-10 from cacao in Costa Rica. in Florida (Tables 1 and 2) and cacao in Costa Rica (Fig. 1). Furthermore, isolates from 1988 and 1992 epidemics of brown rot in Florida produced the same pattern as isolates from more recent ones (Table 1). The patterns for isolates of $P$. nicotianae from citrus soil and foliar epidemics in Texas were the same as for isolates of P. nicotianae from soil and fruit in Florida (Figs. 1 and 2). The patterns for $P$. citrophthora from citrus roots and bark in California were identical and distinct from $P$. palmivora and $P$. nicotianae (Figs. 1 and 2). Other Phytophthora spp. that do not attack citrus but are found in the same agricultural areas of California, Florida, and Texas produced phenotypes unique from the citrus pathogens, except as noted above (Fig. 2).

The utility of CAE as a rapid diagnostic tool was demonstrated for isolations from both fruit and soil. Fruit from inoculation tests with mycelial growth on the surface was scraped and the mycelium transferred to a microcentrifuge tube. The samples from $P$. nicotianae-, $P$. palmivora-, and $P$. citrophthora-infected fruit produced the same patterns as the isolates used for inoculations and were easily distinguished from one another (Figs. 1 to 3). Isolates P66 and PL10 that did not produce symptoms on fruit also did not give a detectable GPI pattern from an extract of the rind at the inoculation site. Single colonies on isolation plates were cut out from the agar to evaluate CAE for diagnosis of unknown colonies. Colonies that were compact and dense (P. palmivora phenotype) were compared with colonies from the same plates that were diffuse and faster growing ( $P$. nicotianae phenotype). The GPI patterns were compared with culture-produced mycelium of each species on the same gels. The patterns were true to type for each Phytophthora sp. and readily distinguishable.

\section{DISCUSSION}

P. palmivora has been reported as a pathogen of citrus in the warm tropics of the Americas, but is not widely recognized as an important problem (8). Conditions for brown rot epidemics in Florida in 1994, 1995, and 1997 were cloudy, periodically wet

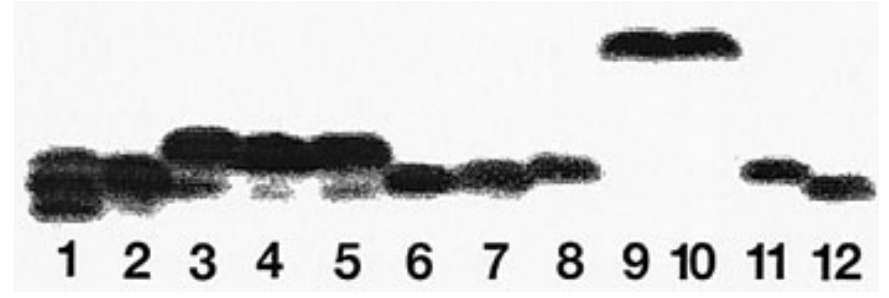

Fig. 2. Cellulose acetate electrophoresis of the isozyme glucose-6-phosphate isomerase for citrus pathogens in Florida, California, and Texas compared with other papillate Phytophthora spp. from the same regions. Lane 1 is $P$. palmivora isolate $\mathrm{P} 48$; lane 2 is $P$. nicotianae isolate $\mathrm{Dd}-1$; lanes 3 to 5 are isolates $P$. citrophthora M259, M189, and M263; lanes 6 and 7 are P. nicotianae isolates P91-28 and P92-19; lane 8 is P. cactorum; lanes 9 and 10 are $P$. citricola M214 and M265 from avocado; lane 11 is $P$. citricola M224 from alfalfa; and lane 12 is $P$. capsici $\mathrm{P} 94-15 \mathrm{~B}$ from chili pepper.

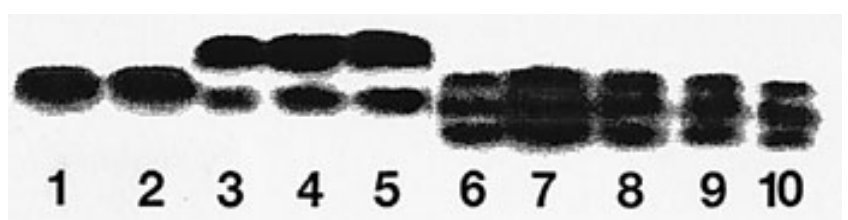

Fig. 3. Cellulose acetate electrophoresis of the isozyme glucose-6-phosphate isomerase for mycelium scrapped from the surface of brown-rotted fruit of Valencia orange inoculated with citrus pathogens. Lanes 1 and 2 are Phytophthora nicotianae isolates Riv-1 and Dd-1; lanes 3 to 5 are P. citrophthora isolates M259, M189, and M140; and lanes 6 to 10 are P. palmivora isolates P99-59-1, P29, P48, EB-1, and P67-1. 
weather with temperatures ranging from 23 to $32^{\circ} \mathrm{C}$ in late summer to late fall, coincident with the final stages of fruit expansion and development of a colored rind. At an optimum temperature of 27 to $30^{\circ} \mathrm{C}$, infection by $P$. palmivora required only 1 to $3 \mathrm{~h}$ of moisture on the surface of fruit (L. W. Timmer and S. E. Zitko, unpublished data). Favorable conditions for fruit infection in late August and early September were 9 to 12 rain events for approximately 3 weeks prior to the development of brown rot symptoms in orchards with poor air movement. Epidemics recurred in the same locations in late September and early October after fewer rain events within shorter periods. Rainfall per event often, but not always, increased prior to the epidemic, confirming that duration and periodicity of fruit wetness were important for brown rot development (9). Diseases appeared to spread laterally if infected fruit did not fall to the ground but remained hanging on the tree as mummies late in the fall (J. H. Graham, unpublished data).

Brown rot epidemics have occurred sporadically in localized areas in the south-central and east-coast production areas since the 1950s and 1960s, but not until severe outbreaks from 1994 to 1997 in the same regions was there further investigation of the causal Phytophthora spp. Whiteside (18) identified isolates from brown rot high in the tree canopy as $P$. citrophthora, distinct from $P$. nicotianae, the cause of root rot and fruit infection near the ground. In this study, we confirmed that the cause of recent epidemics was not commonly occurring $P$. nicotianae, but $P$. palmivora, a newly reported species causing brown rot in Florida. $P$. palmivora was first detected in Florida from soil samples in two east-coast orchards by Zitko et al. (20). They concluded that the fungus was restricted in occurrence in Florida citrus orchards, but had the potential to become a more serious pathogen of bark and fruit because it produced more severe infection of fibrous roots more rapidly than $P$. nicotianae (19). Similarities of location, severity, and restricted occurrence between the current and earlier outbreaks of brown rot in Florida $(9,17)$ suggest that earlier epidemics may have been caused by $P$. palmivora, rather than $P$. citrophthora as previously reported (18). P. citrophthora has yet to be associated with recent epidemics and confirmed in Florida orchard soils.

The morphology, mating behavior, and CAE isozyme analysis of brown rot isolates from 1988 to 1997 matched previously identified isolates of $P$. palmivora from citrus roots, other host plants, and other locations, but differed from $P$. citrophthora in California and $P$. nicotianae in Florida and Texas. The isozyme GPI provided optimum activity and resolution with small quantities of mycelium and gel run times of 45 to $75 \mathrm{~min}$. Since the number of genetic loci that specify the isozymes for each fungal genotype is unknown, the complex banding patterns for some of the Phytophthora spp. cannot be strictly interpreted. GPI is a dimeric enzyme in $P$. infestans (2). Homozygous genotypes form a single band (e.g., P. nicotianae) (Fig. 1), whereas heterozygous genotypes have three bands: two homodimer bands and one heterodimer band of twice the intensity halfway between the other two bands (e.g., P. palmivora) (Fig. 1). The three citrus pathogens produced patterns of one to three bands with GPI, whereas the isolates produced less distinctive patterns of two bands with $\mathrm{MDH}$.

Oudemans and Coffey (12) and Mchau and Coffey (10) analyzed up to 19 different isoenzyme loci, including GPI and MDH, to conclude that $P$. palmivora and $P$. nicotianae had the lowest levels and $P$. citrophthora a much higher level of genetic diversity among 12 papillate species of Phytophthora studied. Oudemans and Coffey (12) designated the isolate of $P$. palmivora from milkweed vine included in our study as electrophoretic type (ET) 4. Although $P$. palmivora is polymorphic at the GPI locus, ET4 was the most commonly occurring ET among the 100 isolates analyzed. Thus, citrus isolates of $P$. palmivora are the same ET as the majority of isolates from subtropical and tropical woody plant hosts (12). Citrus isolates of $P$. palmivora are distinguishable by GPI phenotype from isolate PA3-1 of $P$. arecae from bamboo palm in south Florida, as predicted from the earlier isozyme study that included the same isolate (12). The isolate of $P$. arecae from "citrus soil" evaluated in that study was $P$. arecae isolate PA3-1 (14), isolated from an artificially infested soil from a citrus inoculation trial conducted by Zitko et al. (20), and thus does not represent a citrus isolate of this species. The distinct GPI phenotypes for avocado and alfalfa isolates of $P$. citricola from California indicate that use of one or two isozyme loci for species identification should proceed with caution. Until more representative worldwide populations of Phytophthora spp. from citrus are evaluated, isozyme analysis should only be applied for analysis of Florida isolates of citrus pathogens.

Because isolates of $P$. palmivora in Florida were monomorphic at the chosen isozyme locus, CAE with GPI provided a rapid, inexpensive, and unambiguous diagnosis of the causal Phytophthora spp. of brown-rotted fruit. Mycelium scraped from the surface of one or two infected fruit held overnight in a resealable plastic bag was sufficient to extract for analysis of GPI activity. The GPI patterns for the three major citrus pathogens were very different and distinct from other papillate Phytophthora spp. that might be present on other hosts in citrus-growing regions. This diagnostic capability was applicable when brown rot caused by $P$. palmivora was in the early stages (less than $1 \mathrm{~m}$ high in the canopy) and the symptoms were indistinguishable from those caused by $P$. nicotianae. Also, washing the fruit surface to recover high numbers of ellipsoidal sporangia versus low numbers of spherical sporangia was useful for quick diagnosis, although shape of sporangia from fruit was quite variable. Otherwise, isolation of pure cultures from fruit for sporangium production required 2 weeks to make definitive observations of morphology.

Likewise, CAE was applicable for accurate identification of $P$. palmivora colonies on soil isolation plates. Colony morphology of $P$. palmivora was compact compared with spreading, faster-growing colonies of $P$. nicotianae on PARPH selective medium. Ellipsoidal sporangia developed within 3 days with $P$. palmivora, whereas sporangium production by $P$. nicotianae was delayed and sparse. Individual colonies of each species were cut directly from PARPH agar plates and processed for detection of GPI.

$P$. citrophthora is the well-recognized pathogen of fruit and trunk bark in coastal, Mediterranean regions with wet, foggy winters and temperatures ranging from 18 to $25^{\circ} \mathrm{C}(6)$. These conditions are quite different from the reported temperature optima for the Florida brown rot and root rot isolates, which range from 23 to $30^{\circ} \mathrm{C}(18,20)$. At the early stage of conducive conditions in August and September, fruit that fell to the ground for various reasons appeared to be significant for buildup of inoculum prior to the first symptoms of brown rot in the tree. Fallen fruit acted as a trap to move $P$. palmivora to the aerial phase from the soil phase, where it existed at low incidence and populations relative to $P$. nicotianae. $P$. palmivora infected fallen fruit and developed sporangia within 48 to $72 \mathrm{~h}$ (L. W. Timmer and S. E. Zitko, unpublished data). When the fruit surface was impacted by rain drops falling from the canopy, sporangia had the potential to disperse. P. nicotianae did not disperse in this manner, though it was also isolated from fallen fruit. This species produced few sporangia on the surface of diseased fruit even after infection was well developed.

In Florida, fruit and foliage on the lower skirt of the canopy often hangs near the soil surface, yet fruit and leaf infection by $P$. nicotianae is not common, because surface soils are well drained and water does not puddle for prolonged periods. Most infection of fruit by $P$. nicotianae near the soil surface is due to splash of infested soil directly onto the fruit, which rarely exceeds $1 \mathrm{~m}$ in height. Thus, in Florida, the occurrence of brown rot symptoms above $1 \mathrm{~m}$ was a good indication that the causal fungus was $P$. palmivora.

In 1997 , on the east coast near where $P$. palmivora was first isolated in Florida, $P$. palmivora and $P$. nicotianae were both present at very high populations in soil $\left(>40\right.$ propagules per $\left.\mathrm{cm}^{3}\right)$. Both species were isolated from severe root rot on structural roots of citrus initially attacked by Diaprepes abbreviatus. Larvae of this root weevil, originally introduced into Florida from Puerto Rico in 
the 1950s, deeply etch the root bark, which predisposes the structural roots to infection by $P$. palmivora as well as the more common $P$. nicotianae $(4,13)$. In these situations, $P$. palmivora is a more aggressive and damaging pathogen than $P$. nicotianae alone, even breaking the resistance of the normally resistant rootstock Swingle citrumelo $(3,4)$. These observations appear to support Zitko and Timmer's (19) contention that, even though P. palmivora is a more aggressive pathogen, it does not compete in the soil under most circumstances. That is, $P$. palmivora only appeared to compete well when the host roots were predisposed by severe wounding caused by larvae of $D$. abbreviatus. Elsewhere in brown rot-affected orchards, $P$. palmivora existed at low populations on fibrous roots, presumably in competition with $P$. nicotianae, until it was baited out of soil and spread to fruit under conducive conditions for sporulation and dispersal. Another suggestion, by Zitko et al. (20), for the localized occurrence of $P$. palmivora was that the pathogen is introduced into orchards from native vegetation such as hammocks of palms, but has not yet infested nursery sites where much wider distribution in the industry may occur.

\section{ACKNOWLEDGMENTS}

Florida Agricultural Experiment Station journal series no. R-06010. This research was supported, in part, by the Florida Citrus Production Research Advisory Council project 961-4. We thank C. Haun and M. Rubio for technical assistance, and S. Farr of Ben Hill Griffin, Inc., and M. Stewart of Turner Foods Corp. for supplying weather data from orchard locations.

\section{LITERATURE CITED}

1. Burnett, H. C., Tucker, D. P. H., Patterson, M. E., and Ridings, W. H. 1973. Biological control of milkweed vine with a race of Phytophthora citrophthora. Proc. Fla. State Hortic. Soc. 86:111-115.

2. Goodwin, S. B., Schneider, R. E., and Fry. W. E. 1995. Use of celluloseacetate electrophoresis for rapid identification of allozyme genotypes of Phytophthora infestans. Plant Dis. 79:1181-1185.

3. Graham, J. H. 1995. Root regeneration and tolerance of citrus rootstocks to root rot caused by Phytophthora nicotianae. Phytopathology 85:111-117.

4. Graham, J. H., McCoy, C. W., and Rogers, S. R. 1997. The Phytophthora-Diaprepes weevil complex. Citrus Ind. 78(8):67-70.
5. Graham, J. H., and Timmer, L. W. 1992. Phytophthora diseases of citrus. Pages 250-269 in: Plant Diseases of International Importance. Vol. III. Diseases of Fruit Crops. J. Kumar, H. S. Chaube, U. S. Singh, and A. N. Mukhopadhyay, eds. Prentice-Hall, Englewood Cliffs, NJ.

6. Graham, J. H., and Timmer, L. W. 1995. Identification and control of Phytophthora species causing brown rot of citrus. Citrus Ind. 76(8):38-39.

7. Hebert, P. D. N., and Beaton, M. J. 1993. Methodologies for isozyme analysis using cellulose acetate electrophoresis. Helena Laboratories, Beaumont, TX.

8. Klotz, L. J. 1978. Fungal, bacterial, and non-parasitic diseases and injuries originating in the seedbed nursery and orchard. Pages 1-66 in: The Citrus Industry, Vol. 5. W. Reuther, E. C. Calavan, and G. E. Carmen, eds. University of California, Division of Agricultural Sciences, Richmond.

9. Knorr, L. C. 1956. Progress of citrus brown rot in Florida, a disease of recent occurrence in the State. Plant Dis. Rep. 40:772-774.

10. Mchau, G. R. A., and Coffey, M. D. 1994. An integrated study of the morphological and isozyme patterns found within a worldwide collection of Phytophthora citrophthora and a redescription of the species. Mycol. Res. 98:1291-1299.

11. Mitchell, D. J., Kannwischer-Mitchell, M. E., and Zentmyer, G. A. 1986. Isolating, identifying and producing inoculum of Phytophthora spp. Pages 63-66 in: Methods for Evaluating Pesticides for Control of Plant Pathogens. K. D. Hickey, ed. The American Phytopathological Society, St. Paul, MN.

12. Oudemans, P., and Coffey, M. D. 1991. A revised systematics of twelve papillate Phytophthora species based on isozyme analysis. Mycol. Res. 95:1025-1046.

13. Rogers, S., Graham, J. H., and McCoy, C. W. 1996. Insect-plant pathogen interactions: Preliminary studies of Diaprepes root weevil injuries and Phytophthora infections. Pro. Fla. State Hortic. Soc. 109:57-62.

14. Ploetz, R. C., and D. J. Mitchell. 1989. Root rot of bamboo palm caused by Phytophthora arecae. Plant Dis. 73:266-269.

15. Timmer, L. W., Sandler, H. A., Graham, J. H., and Zitko, S. E. 1988. Sampling citrus orchards in Florida to estimate populations of Phytophthora parasitica. Phytopathology 78:940-944.

16. Tsao, P. H. 1971. Chlamydospore formation in sporangium-free liquid cultures of Phytophthora parasitica. Phytopathology 61:1412-1413.

17. West, E., Cohen, M., and Knorr, L. C. 1954. Brown rot of citrus on the tree in Florida. Plant Dis. Rep. 38:120-121.

18. Whiteside, J. O. 1970. Factors contributing to the restricted occurrence of citrus brown rot in Florida. Plant Dis. Rep. 54:608-611.

19. Zitko, S. E., and Timmer, L. W. 1994. Competitive parasitic abilities of Phytophthora parasitica and P. palmivora on fibrous roots of citrus. Phytopathology 84:1000-1004.

20. Zitko, S. E., Timmer, L. W., and Sandler, H. A. 1991. Isolation of Phytophthora palmivora pathogenic to citrus in Florida. Plant Dis. 75:532-535. 